IZA DP No. 9929

Inequality from Generation to Generation:

The United States in Comparison

Miles Corak

May 2016 


\title{
Inequality from Generation to Generation: The United States in Comparison
}

\author{
Miles Corak \\ University of Ottawa \\ and IZA
}

Discussion Paper No. 9929

May 2016

IZA

P.O. Box 7240

53072 Bonn

Germany

Phone: +49-228-3894-0

Fax: +49-228-3894-180

E-mail: iza@iza.org

Any opinions expressed here are those of the author(s) and not those of IZA. Research published in this series may include views on policy, but the institute itself takes no institutional policy positions. The IZA research network is committed to the IZA Guiding Principles of Research Integrity.

The Institute for the Study of Labor (IZA) in Bonn is a local and virtual international research center and a place of communication between science, politics and business. IZA is an independent nonprofit organization supported by Deutsche Post Foundation. The center is associated with the University of Bonn and offers a stimulating research environment through its international network, workshops and conferences, data service, project support, research visits and doctoral program. IZA engages in (i) original and internationally competitive research in all fields of labor economics, (ii) development of policy concepts, and (iii) dissemination of research results and concepts to the interested public.

IZA Discussion Papers often represent preliminary work and are circulated to encourage discussion. Citation of such a paper should account for its provisional character. A revised version may be available directly from the author. 


\section{ABSTRACT \\ Inequality from Generation to Generation: The United States in Comparison}

To understand the degree of intergenerational mobility in the United States, and the differences between Americans and others, it is important to appreciate the workings and interaction of three fundamental institutions: the family, the market, and the state. But comparisons can also be misleading. The way in which families, labor markets, and government policy determine the life chances of children is complicated; the result of a particular history, societal values, and the nature of the political process. It might be one thing to say that the United States has significantly less intergenerational mobility than Denmark or Norway, but it is entirely another thing to suggest that these countries offer templates for the conduct of public policy that can be applied on this side of the Atlantic. There is no way to get from here to there. It is helpful to focus on a particularly apt comparison, that between the United States and Canada, in order to illustrate how the configuration of the forces determining the transmission of inequality across generations differs in spite of the fact that both of these countries share many other things in common, particularly the importance and meaning of equality of opportunity and the role of individual hard work and motivation.

JEL Classification: J62, J68

Keywords: intergenerational mobility, equality of opportunity

Corresponding author:

Miles Corak

Graduate School of Public and International Affairs

University of Ottawa

55 Laurier Avenue East, Room 3130

Ottawa ON K1N 5N5

Canada

E-mail:mcorak@uottawa.ca 


\title{
Inequality from generation to generation:
}

\author{
the United States in Comparison
}

\section{Introduction}

Snapshots leave more to the imagination than movies. This is certainly the case when it comes to measuring and understanding inequality. Whether the degree of inequality in a society is "too high" or "too low" is hard to say, and therefore it is hard to imagine what the public policy implications should be. How did it arise? What will happen to it in the future? These seem to be reasonable questions to ask in trying to interpret a picture taken at a particular point in time.

Knowing the dynamics of inequality over the horizon of a working lifetime is certainly important in developing a fuller picture; but particularly important as well is a movie whose frames play out over an even longer horizon, between two generations or more. How does inequality get transmitted from parents to their children? Do low income families raise children who grow up to be low income adults and in turn raise the next generation of poor children? Or for that matter how likely is it that rich kids become the next generation of rich adults? Seeing a society from this perspective gives more context, and helps us to understand how inequality of outcomes came about and how it will evolve.

When our focus is on changes in inequality from generation to generation, that is when we are speaking about inter-generational mobility, we are able not only to describe how inequality is transmitted from parents to children, but just as importantly this description speaks to underlying values - like equality of opportunity - that in some sense might allow us to say that there is "too" much or "too" little inequality in society.

Indeed, "equality of opportunity", as opposed to "equality of outcomes", is a value that Americans hold dear. The idea that individual talent, energy, and motivation determine outcomes and accomplishments, as opposed to family background and status, is central to living the "American Dream." A poll conducted by the PEW Charitable Trusts in 2009 found that about three-quarters of Americans strongly held the view that the American Dream meant "being free to accomplish anything with hard work," and about $90 \%$ said hard work and having ambition were either essential or very important to getting ahead in life. (Economic Mobility Project 2009).

But the major message of this chapter is that there is a disconnect between the way Americans see themselves and the way the economy and society actually function. Many Americans may hold the belief that hard work is what it takes to get ahead, but in actual fact the playing field is a good deal stickier than it appears. Family background, not just individual effort and hard work, is importantly related to one's position in the economic and social hierarchy. This disconnect is brought into particular relief by placing the United States in an international context. In fact, children are much more likely as adults to end up in the same place on the income and status ladder as their parents in the United States than in most other countries.

These comparisons beg the question as to why. Addressing this question is the second major message of the chapter. To understand the degree of intergenerational mobility in the United States, and the differences between Americans and others, it is important to appreciate the workings and interaction of three fundamental institutions: the family, the market, and the state. But comparisons can also be misleading. The way in which families, labor markets, and government policy determine the life chances of children is complicated; the result of a particular history, societal values, and the nature of the political process. 
It might be one thing to say that the United States has significantly less intergenerational mobility than Denmark or Norway, but it is entirely another thing to suggest that these countries offer templates for the conduct of public policy that can be applied on this side of the Atlantic. There is no way to get from here to there. For this reason the third major objective of the chapter is to focus on a particularly apt comparison, that between the United States and Canada, and to illustrate how the configuration of the forces determining the transmission of inequality across generations differs in spite of the fact that both of these countries share many other things in common, particularly the importance and meaning of equality of opportunity and the role of individual hard work and motivation.

\section{Focusing the lens: a first look at measuring intergenerational mobility}

The measurement and description of the degree to which family background is related to the adult attainments of children has a long history in the social sciences, and has been done in a number of different ways. Broad swaths of the literature in sociology deal with the degree to which children as adults have the same status among their counterparts as their parents did a generation earlier. "Status" is often measured on the basis of occupation or some related indicator of the position or degree of control an individual may have in the workplace. It is also often related to "class", and the objective in this literature is to describe the degree of mobility across distinct thresholds associated with this concept.

For some decades there has also been a focus on earnings and income as the outcomes of interest. This has naturally led to the most often used statistic in this literature, namely, the "intergenerational elasticity in earnings", which is the percentage difference in earnings in the child's generation associated with the percentage difference in the parental generation. For example, an intergenerational elasticity in earnings of .6 tells us that if one father makes $100 \%$ more than another then the son of the high income father will, as an adult, earn $60 \%$ more than the son of the relatively lower income father. ${ }^{1}$ An elasticity of 0.2 says this $100 \%$ difference between the fathers would only lead to a $20 \%$ difference between the sons. A lower elasticity means a society with more mobility.

The primary focus of much of this research has been on the father-son relationship because it is the least complicated and, because of the availability of data, the most convenient to obtain reliable estimates from a large number of different countries for purposes of international comparisons. ${ }^{2}$ Comparisons involving

\footnotetext{
${ }^{1}$ Slightly more formerly, if $Y$ represents permanent income and $t$ is an index of generations, then the relationship between the adult outcomes of children and their family background can be represented as: $\ln Y_{i, t}=\alpha+\beta \ln Y_{i, t-1}+\varepsilon_{i, t}$. In this expression the adult income (in natural logarithms) of family $i$ 's child, $\ln Y_{i, t}$, is made up of three components: the average income of the children of generation $t$ (as represented by $\alpha$ ); the deviation from this average reflecting family income $\left(\beta \ln Y_{i, t-1}\right)$; and all other influences not associated with parental income and including luck $\left(\varepsilon_{i, t}\right)$. The intergenerational elasticity in earnings is $\beta$. If this expression is converted from logarithms to dollars it would be expressed as $Y_{i, t}=\exp (\alpha) \times \exp \left(\beta \ln Y_{i, t-1}\right)=\exp (\alpha) \times\left(Y_{i, t-1}\right)^{\beta}$ if $\varepsilon_{i, t}$ is ignored. This implies that the ratio of incomes for children from high income $(H)$ and low income $(L)$ backgrounds is $Y_{H, t} / Y_{L, t}=\left(Y_{H, t-1} / Y_{L, t-1}\right)^{\beta}$, that is, the ratio of their parents' incomes raised to the $\beta$ power. A clear introduction to this statistic is offered by Solon (2008), and more intuition on its nature and use is available in Corak $(2006,2004)$ and Mulligan (1997).

${ }^{2}$ But clearly a single statistic cannot give a full picture of the nature of generational mobility. The elasticity refers to relative mobility through time, but it should also be recognized that a certain percentage change in earnings may mean, in absolute terms, something different across countries if the variation in the underlying earnings distributions is different. It may not take much of a change in earnings to make say a $10 \%$ change in one's position in countries like Norway or Denmark while at the same time taking a good deal more to make the same percentage change in the United States, where there is a good deal more dispersion in the earnings distribution. For this reason a standardized measure of intergenerational mobility, the correlation coefficient which refers to mobility in terms of the standard
} 
daughters and mothers, or a focus on relationships that also account for marital choices and not just labour market choices, have also been studied. There are also studies addressing, among others, total income, self-employment income, assets, and receipt of government transfer payments like welfare and unemployment insurance.

We should be clear from the very beginning that the use of the intergenerational elasticity of earnings is an exercise of description, and in and of itself does not offer a story about the underlying causal forces, and as such, does not lead to clear policy recommendations.

We should also be clear that this is a much more difficult statistic to measure than those associated with cross-sectional inequality, and in fact there has been a good deal of controversy about these measurement issues. This is because of the data requirements and challenges of translating theoretical concepts into practical measures.

To accurately measure the intergenerational earnings elasticity requires estimates of the lifetime earnings prospects of both parents and their children in their adulthood. Because earnings tend to rise over the life cycle but annual earnings fluctuate a great deal, good estimates of lifetime earnings require having several years of earnings data during a period in the life cycle when individuals are established in their career jobs (when they are 40 to 50 or so years of age), and these estimates must be available for both the parent and the child. As such the members of a family have to be followed and connected to each other over a period that easily spans several decades.

A good deal is at stake in getting these measurement issues right: they have been shown to matter for the ultimate statistic, and hence description of how families and labor markets work. Becker's $(1988,10)$ summary of the state of the literature as it existed up to about the mid-1980s implied an intergenerational elasticity of about 0.2 . But this empirical literature has evolved with the availability of more accurate and more representative data. Corak (2006) suggests that the best estimate for the United States is somewhere between 0.4 and 0.6 .

Figure 1 shows a 22 country comparison of intergenerational elasticity estimates. The estimates range from less than 0.2 in countries like Denmark, Norway, and Finland to a high of almost 0.7 in Peru. Part of the variation across the countries is due to the process of economic development, with lower income countries generally having a higher proportion of inequality transmitted across the generations. And part of the reason for some of the very high estimates have to do with the exclusion of particular groups in the full participation in the labor market and society, be it some segments of the aboriginal population in Peru, and to some extent the rural population in China.

But there is more to this variation than the overall level of economic development or broad structural factors. If we restrict our attention to the rich countries there remains considerable variation, with the United States standing out, along with Italy and the United Kingdom, as the least inter-generationally mobile. In these countries the estimate is in the neighbourhood of 0.5 , being two or more times as large as the most mobile countries who are characterized by estimates of about 0.2 or even a bit less.

The natural question to ask is why?

deviation of the earnings distribution, is also often used. As an example see Bjorklund and Jantti (2011) who show that among the countries they examine there is less of a difference in correlation coefficients than in elasticities. 


\section{A framework for understanding cross-country differences}

To understand these differences we need to appreciate the possible underlying causes of generational mobility, and an important starting point is Solon (2004) who has adapted a standard perspective in the economics literature and made it appropriate for comparisons across countries. Very broadly speaking, the reasons for the differences in the intergenerational elasticity across countries has to do with the role of three fundamental institutions determining the life chances of children - the family, the labor market, the state — and the different balance struck between their influence across countries.

Solon's model invites us to think of families differing in their capacities and resources to invest in their children, but also as facing different incentives to do so according to their socio-economic status and the social context in their country. While some of these capacities and incentives to invest in children may be genetic or due to family history and culture, others are influenced by how families interact and interface with the labour market and public programs. It is these later influences that are related to public policy and choices.

Parents invest in and influence the adult outcomes of children in a whole host of ways, but these investments can have particularly important implications at certain stages of a child's life. We should not therefore understate the role of families, but at the same time we need also to appreciate the context within which they live and the social supports offered to them.

The argument is often made that a particularly important window of opportunity in a child's development occurs during the early years, up to about five years of age. This meshes very much with developments in the science of early brain development. The central idea is that the stimulation infants and young children receive from their environment influences their neural development and will ultimately define the outer limits of their capabilities. Children raised in families at the high end of the socio-economic scale are more likely to be exposed to a stimulating environment that leads to an advantageous path in life with respect to health, cognitive development and social skills. If the brain does not receive the requisite environmental stimulation at certain critical periods, the window of opportunity closes and development fails to occur. (Knudsen, Heckman, Cameron, and Shonkoff, 2006.)

This so-called "neural sculpting" occurs at different times for different brain functions, but timing is important. The point is that this process establishes the "initial conditions" of a life and sets the individual down a particular pathway, a pathway in which a series of cumulative experiences may set further constraints or present further opportunities. The series of steps leading through important transitional periods in life look something like this: socio-economic circumstances early in life (and even in the prenatal period) $\rightarrow$ birth weight and cognitive/social/emotional development $\rightarrow$ readiness to learn $\rightarrow$ language development $\rightarrow$ behavioral problems in school and educational achievement $\rightarrow$ labour market success and job characteristics $\rightarrow$ stress, mental well-being, socio-economic status, success in family formation $\rightarrow$ parenting.

The intergenerational earnings elasticity is a summary relationship of the overall outcome of a whole series of gradients that appear at each of these steps. Parents influence child outcomes at each of these stages, but outcomes at any one stage have their roots in earlier stages and child's cumulative experience up to that point. Someone born to parents with low income faces a higher risk of less successfully transiting through these stages and of ending up in a precarious labor market situation, which in turn diminishes his or her capacity for positive parenting. This raises the odds of a generational cycle of poverty, but money is as much the result as the cause of the vicious circle.

For example, the child of a high income, dual-earner couple (with perhaps only one other child) may well be raised in an environment with more resources that improve his or her future adult prospects than the 
child of a single parent with limited education. These resources are both monetary and non-monetary. The advantaged household will certainly be able afford more things and activities for the child, but may also be more likely to spend more time with the child and offer linkages and contacts to the neighborhood and community that will both nurture and offer opportunities for growth and advancement. The support parents offer may extend well into adolescence by helping to direct their children through the labor market, offering advice and contacts as they get their first jobs and establish a foothold that will influence their career prospects. Consequently, we can expect the intergenerational elasticity to differ across countries for reasons associated with demographics, family formation, single parenthood, as well as parenting skills and time devoted to children.

As another example, an increase in the cost of human capital investment, such as in market-based provision of child care or health care, private primary schooling, or higher college tuition fees, will imply lower human capital investment. In a similar way a higher potential return to human capital will create an incentive for more investment. Solon (2004) takes the rate of return to education as an indicator of the degree of inequality in the labour market, and shows that societies with labor markets characterized by more cross-sectional inequality - that is, a higher return to education-will be less generationally mobile. This is because a higher income, dual earner family with fewer children not only has a higher capacity to invest in the education of their children than a single parent low income family, but also because the incentives to do so are greater. Inequality in demographics and labor markets in the here and now will have an influence on the degree of inequality in earnings in the next generation. Consequently we can expect the intergenerational elasticity to differ across countries for reasons associated with the costs and returns of investing in a child's human capital, the way in which the labor market works and how "good jobs" are obtained, and the income inequalities between parents.

But Solon (2004) also suggests that public policy can both accentuate and dampen the influence of labor market inequality. He shows that generational mobility is promoted by "progressive" public programs, those that are of relatively more benefit to the relatively less well off. Two countries may spend the same fraction of their gross domestic product on education, but if this spending is directed to high quality early childhood, primary and secondary schooling it is likely to be of relatively more benefit to families lower in the socio-economic scale than if it was directed to the subsidization of tertiary education. In fact, this refers to more than just public transfers or publicly provided programs directed to children: it also includes all aspects of public actions that influence the relationship between families and the labor market. The structure of taxation and regulations is also part of the story. Hacker and Pierson (2010) focus on changes in these policies to explain the increase in cross-sectional inequality in the United States, but their analysis also has longer-term implications for intergenerational mobility.

In a rough way we can see the outcomes of these forces at work in Figure 2, which plots the intergenerational earnings elasticities presented in Figure 1 against a cross-sectional measure of inequality (the Gini Coefficient). More inequality at a point in time is associated with less generational mobility. Once again, this picture is one of association. The underlying causes relate to the process of child development and the role of socio-economic inequalities influencing it, but these forces may differ in their significance across these countries: in some early childhood development may be the decisive factor, while in others it may be limited access to quality tertiary education due to early tracking of students during the primary years, and others still it may be due to labor markets in which access to good jobs is determined by family contacts, discrimination, or outright nepotism.

Haskins and Sawhill (2009) offer a clear portrait of the life chances of American children as the outcome of the interaction between family background and resources, growing inequalities in the labor market, and changes in government policy. Their analysis offers the kind of detail and institutional backdrop to interpret these raw statistics. To appreciate which aspects of demography, of labor markets, and of government policy are central in determining different outcomes in a comparative framework would 
require an analysis with this kind of detail across many countries. This is no small challenge, but one comparison that may be both feasible and apt is that with Canada because the nature of the family and the structure of labor markets are broadly similar between these two countries.

\section{The United States and Canada}

The information in Figure 1 suggests that the intergenerational earnings elasticity of 0.47 in the United States is more than twice as high as the Canadian estimate of roughly 0.20 , but this likely even understates the difference between the two countries. Corak (2010) suggests that the estimates calculated by Mazumder $(2005 \mathrm{a}, \mathrm{b})$, which are as high as 0.61 , are more directly comparable to estimates of about 0.23 produced with Canadian data by Corak and Heisz (1999): both studies using administrative data on virtually the same age cohorts of men at the same period of time. This suggests that the intergenerational elasticity between father and son earnings is almost three times as high in the United States as it is in Canada.

This difference is the result of different patterns in the degree of mobility at the two extremes of the earnings distribution. In both countries there is a considerable degree of mobility among the broadly defined middle earnings group, but both the sons of high and low earning fathers are more likely to grow up to be, respectively, high and low earning adults.

In the United States $26 \%$ of the sons born to fathers in the top 10 percent of the earnings distribution grow up to have earnings that place them in turn in the top $10 \%$, and the majority of these sons are in at least top $30 \%$ of their earnings distribution, while only $3 \%$ fall to the bottom ten percent. There is also stickiness in earnings at the top in Canada, but not as great: $18 \%$ of top decile sons remain in the top decile, about $40 \%$ are in the top $30 \%$ and about $8 \%$ fall to the bottom. Similarly there is stickiness across the generations for sons raised by low earning fathers, and once again more so in the United States, where $22 \%$ of bottom decile sons remain in the bottom $10 \%$ as adults, and one-half remain in the bottom $30 \%$, In Canada 16\% remain in the bottom, while about 4 in ten remain in the bottom $30 \%$ of the earnings distribution. (Corak 2010, figures 2 and 3.)

In general there is somewhat more upward mobility from the bottom in Canada than in the United States, with Canadian sons born to fathers in the bottom third of the earnings distribution more likely to rise into the top half of their adult earnings distribution than their American counterparts. (Corak 2010, figure 4.)

This is a particularly important difference, and in part reflects the fact that children in the bottom of the income distribution are less well off in an absolute sense in the United States than in Canada. Greater inequality in the American earnings distribution is reflected in the monetary circumstances of children. Corak, Curtis and Phipps (2011, figure 4) show that if Canadian children were placed in the overall American income distribution, their family income would tend to be considered as lower middle class, being disproportionately between the second and fifth deciles. About two-thirds of Canadian children would be found above the bottom tenth of the income distribution but no higher than the middle. When American children are placed in the overall income distribution they are more likely to be at the very bottom and the very top. ${ }^{5}$

But this difference in monetary resources is also reflected in a host of indicators associated with nonmonetary resources, particularly with family resources and other social and community supports. In Canada children are more likely to be living with a mother who is married, and more likely to be living

\footnotetext{
${ }^{5}$ It shoud be noted that these comparisons are based strictly upon monetary resources obtained from the labor market and do not account for the role of taxes and transfers, and particularly in-kind transfers.
} 
with both biological parents. About three-quarters of Canadian children younger than 13 live with both biological parents, while in the United States this proportion is about two-thirds. Further, in the United States mothers tend to be younger, with teenage births being more common. This is particularly so for lone mothers, where in addition to being younger and less educated they also have more children than their Canadian counterparts.

All of this implies that not just monetary resources, but also non-monetary resources - particularly those associated with the time parents spend with their children - are likely to be less enriching for the children of the disadvantaged in the United States. While it is difficult to obtain comparable information on time use, parenting style, and other non-monetary investments parents make in their children, Corak, Curtis and Phipps (2011) note that children in low income and lone parent families are less likely to be read to. This said, the proportion of low income children read to daily, at almost 55\% in Canada versus about onethird in the United States, is significantly different.

The care and time devoted to children also depends upon how families interface with the labor market, and the alternative care arrangements available to their children. As suggested labor markets are more polarized in the United States, and there are different patterns of labor force participation in the two countires. "Parental participation in the labour market is both cause and effect of child care arrangements. The choice or need to work means that parents must find alternative arrangements for their children; the availability of care outside of the home offers opportunities to work or to work more hours." (Corak, Curtis, and Phipps 2011, page 87 ).

In fact, Canadian mothers have higher labor force participation rates, but parents who are in the labor market in the United States work longer hours. In the United States mothers are more likely to work fulltime or not at all, with about $40 \%$ of children having mothers who worked 40 or more hours per week. In Canada only about one-quarter of children are in this situation, there being a greater tendency for mothers to work part-time. In the United States lone mothers are more likely to be working than married mothers, with only one-fifth not working at all compared to almost one-third of married mothers. About one-half of lone mothers work more than 40 hours per week in the United States, but in Canada only about onequarter do so.

As suggested, labor market participation is both cause and effect of the availability of alternative child care arrangements, so these differences are mirrored in differences in care arrangements for young children. Over one-half of all children up to two years of age are cared for exclusively by their parents in Canada, compared to four in ten in the United States. This difference likely reflects the very different maternity and parental leave available for working mothers of newborn children.

Parental benefits are much more generous in Canada with mothers of newborns who had sufficient work experience being provided with the opportunity to stay home for up to 25 weeks after the birth of their child during the 1990s, and with this package of benefits, administered by the federal government through the national unemployment insurance program, being extended to one year in 2001. Maternity benefits are much more limited in the United States. Parents are entitled to 12 weeks of leave without pay if they work in a company with more than 50 people, but with there being a tax deduction for daycare when it is used because of parental employment. 
Corak, Curtis, and Phipps (2011) conclude their much more extensive statistical review by stating that the family context in which children are raised in the United States is more challenging than in Canada, raising the risks that some children will not see the full development of their capabilities. American labour markets are also more unequal raising the stakes for child outcomes, both elevating opportunities and heightening risks. Finally, public policy is less "progressive," not compensating in the same degree for family background and labour market inequality (Corak, Cutis, and Phipps 2011, page 102).

This also relates to a number of measures of human capital, including mental and physical health as well as those associated with education. Overall outcomes are on average higher in Canada, and there is less disparity.

For example, education outcomes that are measured both by the mothers' assessment of the child's performance and on tests administered to the child indicate significant differences in outcomes between these two countries. Canadian four year olds score significantly higher on comparable tests of school readiness (the Peabody Picture Vocabulary test). American mothers of school aged children at the bottom of the socio-economic scale are twice as likely to report that their children are performing below the middle or near the bottom. And according to other tests of mathematics and literacy skills young teens perform on average better in Canada than in the United States. While the schooling system does not seem to significantly narrow initial gaps, it remains unclear as to the extent to which they are amplified or what particular institutional designs and at what particular stages can contribute to narrowing them.

\section{Conclusion}

The nature of inequality at any point in time can be better understood if we appreciate the extent to which it is related to family background, the extent to which one's starting point in life in some sense preconditions ultimate adult social and labor market outcomes.

If rich children are predestined to grow up to be rich adults, and if poor children are similarly predestined to be the next generation of those living in poverty, then inequalities of outcomes are in some sense the result of rigid structures in our society that may lead us to question the extent to which there is equality of opportunity.

On the other hand, if the same degree of inequality is associated with a fluidity of status across generations, with poor parents as likely to raise children who will be top earners as rich parents, then there is less reason to question the existence of equality of opportunity.

There is in fact a good deal of fluidity in the American earnings distribution across the generations with the children of most middle earning parents experiencing outcomes that are not strongly associated with their parents' income levels. But even so, on average, the United States stands out as being among the least generationally mobile among the rich countries, and in particular the overall degree of relative earnings mobility across the generations is almost three times greater in Canada, a country to which it might be most apt to make a comparison. This difference is due to a greater stickiness in earnings across the generations at both the top and the bottom.

At the broadest level we should understand the cross-country differences in the transmission of inequality as arising from differences in the investments these societies make in their children as well as differences in the returns to these investments. This process reflects the workings of the family, the structure of labor markets and how families interact with them, and the role of public policy. Inequality at a point in time is both the outcome and cause of the degree to which economic status is passed across the generations. 
The greater the capacity of families to invest in their children, both in monetary and non-monetary terms, the more likely children will develop the human capital to succeed in marriage and labor markets. The more equal the returns to education in the labor market, the lower the stakes and the more level the incentives to make these investments. And finally, the more progressive public policy-that is the more relative benefit it is to the relatively disadvantaged - the more level the playing field.

All of these factors come into play in understanding the differences in the degree of generational mobility between the United States and Canada, and for that matter between the United States and other countries.

It is unlikely that the degree of generational earnings mobility will change significantly in the United States, at least for the current generation of children growing into adulthood, without there being important changes in the circumstances of the least advantaged. These changes include demographic changes that increase the capacity of parents to invest in the early years of their children's lives - a decline in single parenthood, increases in parental education and age at first birth, and increases in both the quality and quantity of time invested in children during their pre-school and early school years.

Further, the very substantial increases in earnings inequality during the past few decades, which in significant part reflect stagnation in the earnings of those in the bottom half of the earnings distribution and important increases in the share of total earnings going to those at the top, also suggests that intergenerational mobility is unlikely to increase. This will be particularly the case if labor market inequalities translate into political power that determines the extent to which progressive reforms can be made to public policy. These include increasing the quality of schooling and health care for the disadvantaged, offering more support to parents raising young children-both monetary but also in terms of parental leave that allows more time to be spent with their children - and improving access to higher levels of education.

Without changes in these underlying factors the transmission of inequality from the current generation to the next will remain a movie that is played to the same script as that viewed by past generations. 


\section{Figure 1}

Comparable estimates of the intergenerational elasticity between father and son earnings for the United States and twenty one other countries

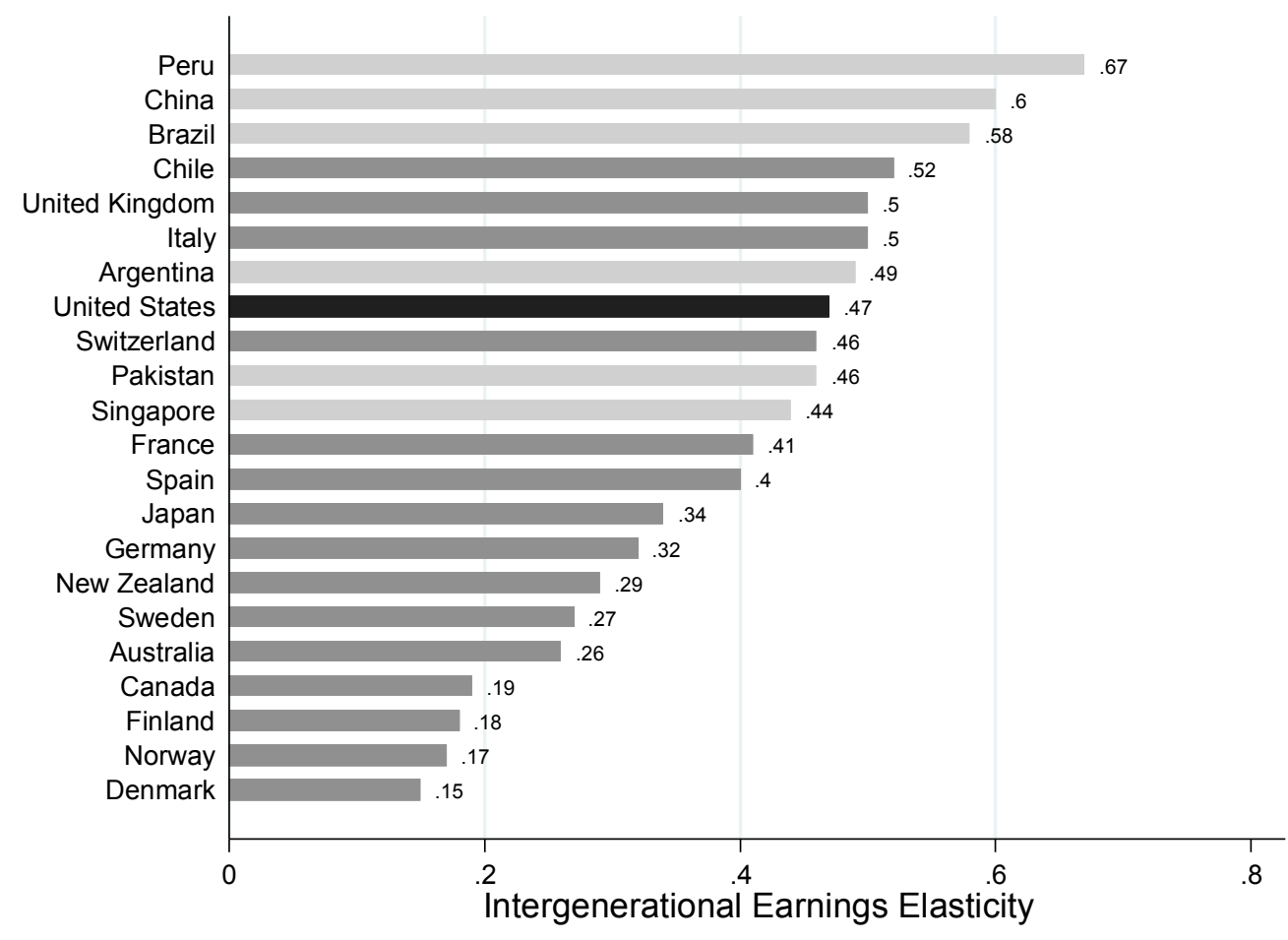

Note: Lightly shaded bars indicate countries that are not member states of the OECD, generally taken to mean lower income countries.

Source: Published estimates collected by the author and using the methods in Corak (2006). 
Figure 2

More inequality at a point in time is associated with less generational earnings mobility in twenty two countries with comparable estimates of the intergenerational elasticity between father and son earnings

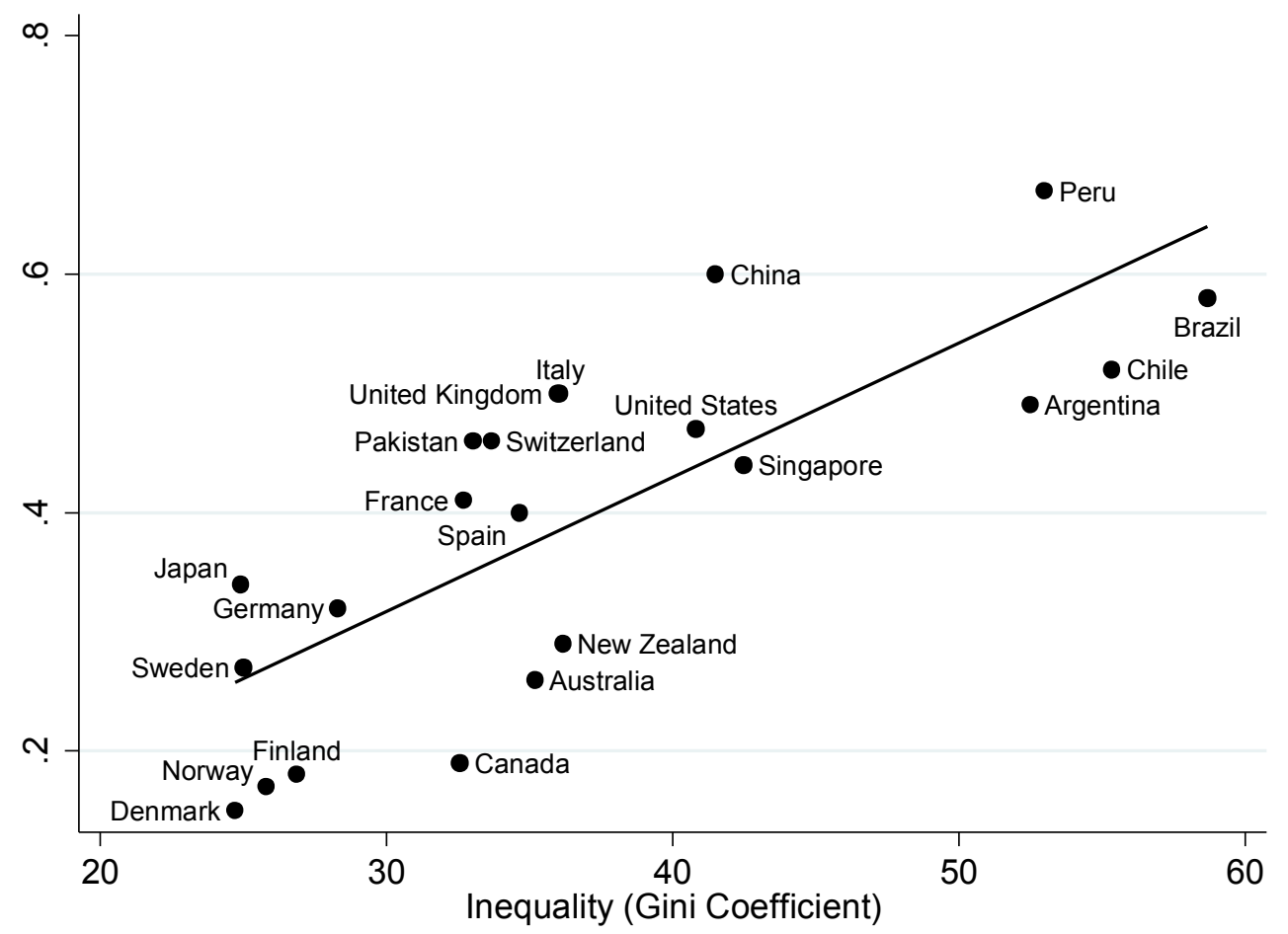

Source: Published estimates collected by the author as presented in Figure 1, and information from the World Bank for the Gini coefficient. Note that data points for Italy and the United Kingdom overlap, and that the upward sloping line is the least squares fitted regression line. 
References

Becker, Gary S. (1988). "Family Economics and Macro Behavior." American Economic Review Vol. 78, No. 1 (March), pages 1-13.

Becker, Gary S. and Nigel Tomes (1986). "Human Capital and the Rise and Fall of Families." Journal of Labor Economics. Vol. 4, pages S1-39.

Becker, Gary S. and Nigel Tomes (1979). "An Equilibrium Theory of the Distribution of Income and Intergenerational Mobility.” Journal of Political Economy. Vol. 87, pp. 1153-89.

Bjorklund, Anders and Markus Jäntti (2011). "Intergenerational economic inequality." In Wiemer Salverda, Brian Nolan and Timothy M. Smeeding (editors). Oxford Handbook of Economic Inequality. Oxford: Oxford University Press.

Corak, Miles (2010). Chasing the same dream, climbing different ladders: Economic Mobility in the United States and Canada. Economic Mobility Project, PEW Charitable Trusts. 25 pages. Available at http://www.pewtrusts.org/news_room_detail.aspx?id=56877.

Corak, Miles (2006). "Do Poor Children Become Poor Adults? Lessons for Public Policy from a Cross Country Comparison of Generational Earnings Mobility." Research on Economic Inequality. Volume 13, pages 143-188.

Corak, Miles (2004). "Introduction.” In Miles Corak (editor). Generational Income Mobility in North America and Europe. Cambridge: Cambridge University Press.

Corak, Miles, Lori Curtis and Shelley Phipps (2011). "Economic mobility, family background, and the well-being of children in the United States and Canada." In Timothy Smeeding, Markus Jäntti, and Robert Erickson (editors). Persitence, Privledge and Parenting: The Comparative Study of Intergenerational Mobility. New York: Russell Sage Foundation. Pages 73-108.

Economic Mobility Project (2009). Opinion Poll on Economic Mobility and the American Dream. Washington: Pew Charitable Trusts. Available at http://www.economicmobility.org/poll2009, accessed July 26, 2011.

Goldberger , Arthur S. (1989). "Economic and Mechanical Models of Intergenerational Transmission." American Economic Review. Vol. 79, No. 3 (June), pp. 504-513.

Grawe, Nathan D. (2004). "Intergenerational Mobility for Whom? The Experience of High and Low Earning Sons in International Perspective." In Miles Corak (editor). Generational Income Mobility in North America and Europe. Cambridge: Cambridge University Press.

Hacker, Jacob and Paul Pierson (2010). Winner-Take-All Politics: How Washington Made the Rich Richer-And Turned Its Back on the Middle Class. New York: Simon and Schuster.

Haskins, Ron and Isabel V. Sawhill (2009). Creating an Opportunity Society. Washington DC: Brookings Institution Press.

Knudsen, Eric I., James J. Heckman, Judy L. Cameron, and Jack P. Shonkoff (2006). "Economic, neurobiological, and behavioural perspectives on building America's future workforce." Proceedings of the National Academy of Sciences. Vol. 103, No. 27 pp. 10155-10162. 
Mazumder, Bhashkar (2005a). "Fortunate Sons: New Estimates of Intergenerational Mobility in the United States Using Social Security Earnings Data." Review of Economics and Statistics. Vol. 87, No. 2 (May), pages 235-255.

Mazumder, Bhashkar (2005b). "The Apple Falls Even Closer to the Tree than We Thought: New and Revised Estimates of the Intergenerational Inheritance of Earnings." In Samuel Bowles, Herbert Gintis, and Melissa Osborne Groves (Editors). Unequal Chances: Family Background and Economic Success. Pages 80-99. Princeton: Princeton University Press and Russell Sage.

Mulligan, Casey B. (1997). Parental Priorities and Economic Inequality. Chicago: University of Chicago Press.

Solon, Gary (2008). “Intergenerational Income Mobility.” In Steven Durlauf and Lawerence Blume (editors). The New Palgrave Dictionary of Economics. Second Edition. London: Palgrave Macmillan.

Solon, Gary (2004). “A model of intergenerational mobility variation over time and place.” In Miles Corak (editor). Generational Income Mobility in North America and Europe. Cambridge: Cambridge University Press.

Solon, Gary (1992). Intergenerational Income Mobility in the United States. American Economic Review, Vol. 82, No. 3 (June), pages 393-408.

Zimmerman (1992). "Regression Toward Mediocrity in Economic Structure." American Economic Review. Vol. 82, No. 3 (June), pages 409-29. 